\title{
Avaliação de manifestações patológicas de escolas públicas do Leste potiguar aplicando a matriz GUT
}

\author{
R. Rodrigues dos $\operatorname{Santos}^{1 *}$, J. L. da Silva Sabino ${ }^{1}$, J. S. de Oliveira Neto ${ }^{1}$, M. V. Dias Marques ${ }^{1}$, \\ C. Patrícia Torres $\mathrm{Cruz}^{2}$ \\ *Autor de Contacto: rodrigorodrigues9798@hotmail.com \\ ${ }^{1}$ Graduando em Engenharia Civil pela Universidade Potiguar, Brasil. \\ ${ }^{2}$ Doutora em Física da Matéria Condensada e Docente da Universidade Potiguar, Brasil.
}

\begin{abstract}
RESUMO
O objetivo deste artigo é analisar as manifestações patológicas das escolas públicas da região Leste do estado do Rio Grande do Norte e apresentar possíveis correções e soluções para tais problemas. Foi realizada uma revisão bibliográfica na literatura, visitas in loco com inspeção visual e registros fotográficos e, em seguida, foram analisados os dados quantitativos através da metodologia da matriz GUT - Gravidade, Urgência e Tendência. Diante dos resultados obtidos, constatou-se a presença de diversas manifestações patológicas nos objetos de estudo. Foi possível concluir que a utilização da metodologia da matriz GUT é uma ferramenta satisfatória para o auxílio à tomada de decisão quanto às atividades de manutenção e reabilitação.
\end{abstract}

Palavras-chave: Edificações, manifestações patológicas, metodologia GUT.

\section{RESUMEN}


El objetivo de este artículo es analizar las manifestaciones patológicas de las escuelas públicas de la región oriental del estado de Rio Grande do Norte y presentar posibles correcciones y soluciones a dichos problemas. Se realizó una revisión bibliográfica, visitas in situ con inspección visual y registros fotográficos, y luego se analizaron los datos cuantitativos a través de la metodología de la matriz GUT - Gravedad, Urgencia y Tendencia. Ante los resultados obtenidos, se constató la presencia de varias manifestaciones patológicas en los objetos de estudio. Se puede concluir que la utilización de la metodología de la matriz GUT es una herramienta satisfactoria para ayudar a la toma de decisiones en las actividades de mantenimiento y rehabilitación.

Palabras clave: Edificios, manifestaciones patológicas, metodología GUT.

\begin{abstract}
The objective of this paper is to analyze the pathological manifestations of public schools in the eastern region of the state of Rio Grande do Norte and present possible corrections and solutions for such problems. It was performed a literature review, on-site visits with visual inspection and photographic records, and then the quantitative data were analyzed through the GUT matrix methodology - Gravity, Urgency and Tendency. In view of the results obtained, the presence of several pathological manifestations in the study objects was verified. Foi possível concluir que a utilização da metodologia da matriz GUT é uma ferramenta satisfatória para o auxílio à tomada de decisão quanto às atividades de manutenção e reabilitação.
\end{abstract}

Keywords: Buildings, pathological manifestations, GUT methodology.

\title{
1. INTRODUÇÃO
}


O Instituto Brasileiro de Avaliações e Perícias de Engenharia do Paraná - IBAPE/PR (2016), aponta que os sistemas e subsistemas de um edifício interagem com o meio ambiente e o ser humano, ocasionando o desgaste deles, tornando assim a manutenção um fator importante para garantia do funcionamento de todo o conjunto. A partir dessa interação, pode vir a acontecer problemas nos sistemas do edifício caso os sistemas não apresentem a qualidade como desejada. Tais problemas são classificados em anomalias ou falhas conforme o Instituto Brasileiro de Auditoria de Engenharia IBRAENG (2015).

De acordo com o IBRAENG (2015) as anomalias são provenientes de vícios ou defeitos construtivos e podem ser classificadas em: Endógenas, exógenas, naturais e funcionais. É recomendado que as anomalias sejam classificadas quanto às características de acordo com o tipo de ocorrência, sendo alguns tipos de tipos de anomalias encontradas nas edificações: fissuras, manchas, oxidações, corrosões, deslocamentos, umidades, vazamentos, infiltrações, descascamentos e outros. As falhas são originadas a partir da ausência de manutenção, sendo classificadas em: de planejamento, de execução, operacionais e gerenciais.

Segundo Martins e Fioriti (2016) as manifestações patológicas podem apresentar sua origem devido a problemas na fase de execução, na fase de uso ou na fase de projeto. Para os autores, o surgimento de fissuras influencia diretamente no comportamento de usuários leigos já que estes concluem que esse tipo de ocorrência não é normal. Felten et al. (2013) aponta que a manutenção preventiva, que apresenta baixo custo, é uma das formas de evitar o aparecimento de manifestações patológicas.

De acordo com Helene (1997), as manifestações patológicas são oriundas da ação de agentes causadores como variação da umidade, cargas, variações térmicas intrínsecas e extrínsecas ao concreto, por componentes biológicos entre outros. Arivabene (2015), aponta que as causas dos problemas patológicos podem ser evitadas e que as estas são provenientes de uma má execução.

Para Silva et al. (2016), fatores como a utilização de materiais inadequados, métodos construtivos não condizentes e erros relativos à técnica e operação contribuem para o surgimento e presença de manifestações patológicas. Dessa forma, todos os sistemas e subsistemas que compõe o conjunto do edifício estão sujeitos ao surgimento de manifestações patológicas, uma vez que os mecanismos causadores agem quando existe uma possível anomalia ou falha.

Os sistemas de acabamento das edificações apresentam maior ocorrência de manifestações patológicas, visto que estas estão expostas constantemente a mecanismos agressivos, tais como umidade, variações de temperatura, vento, insolação e agentes biológicos conforme aponta Silva et al. (2016). Ainda segundo os autores, as fachadas tornam-se um dos sistemas mais afetados devido receberem maior incidência de intempéries. Schardong e Pagnussat (2011) verificaram que tanto em lajes quanto em paredes, as manifestações patológicas mais recorrentes são fissuras, umidades, recalques do piso e descolamento de pintura.

Silva et al. (2016) verificou que 31,5\% dos casos estudados apresentaram relação com o desempenho entre revestimento e substrato de fachadas, sendo a principal manifestação patológica presente. Em seguida, manifestações oriundas de deformações, percolação de líquidos e manifestações na pintura, apresentaram 29,4\%,21,8\% e 17,3\% respectivamente.

GALLETTO e ANDRELLO (2013) em seus estudos, encontraram que as principais manifestações patológicas em fachadas com revestimentos cerâmicos são manchas e som cavo, descolamento das placas cerâmicas e falhas no rejuntamento. Martins e Fioriti (2016) apontam que as manifestações mais encontradas foram fissuras, nichos, irregularidades geométricas, manchas escuras, exposição e corrosão da armadura, eflorescências e lixiviação. Problemas como desplacamento de materiais e som cavo foram detectados em revestimentos que foram aplicados sobre estruturas de concreto, uma vez que a camada de revestimento descolava na interface entre estrutura e chapisco, conforme CARASEK e CASCUDO (2007). Ainda segundo os autores, em algumas situações em que mesmo 
sem o descolamento do revestimento, tais locais apresentavam som cavo. Constatou-se também fissuras mapeadas, formando ângulos próximos a $90^{\circ}$ sem orientação.

CARASEK e CASCUDO (2007) realizaram estudos sobre a resistência de aderência entre as camadas de revestimentos e o substrato (estrutura de concreto). Foi constatado que nas regiões onde não se tinham fissuras presentes e nem som cavo, as rupturas aconteceram em maior parte na interface entre chapisco e estrutura apresentando resultados altos com média 0,32 MPa. Nas regiões onde havia a presença de fissuras e próximas onde o som cavo era observado, o resultado médio foi de $0,11 \mathrm{MPa}$ em relação a região que não apresentava fissuras e som cavo. Quanto a resistência de arrancamento do revestimento aplicado sobre a alvenaria, os resultados apresentaram média de $0,29 \mathrm{MPa}$, onde o rompimento acontecia principalmente entre o chapisco e a base.

Os autores, CARASEK e CASCUDO (2007), concluíram que, a partir dos resultados do ensaio de aderência foram notados dois principais problemas em fachadas com revestimento cerâmico: a baixa aderencia entre a camada de chapisco e substrato (estrutura de concreto) que pode ter sido causada na ausência de limpeza do substrato, e a fissuração no revestimento encontrada de forma mapeada ou sem orientação com fissuras em ângulos próximos de $90^{\circ}$, demonstrando que a argamassa sofreu retração.

Felten et al. (2013) analisaram problemas presentes em marquises de concreto armado e verificaram que $90 \%$ das amostras analisadas apresentaram algum tipo de manifestação patológica. Os autores ressaltam que, das análises em que foram respondidos os questionários aplicados sobre a realização de manutenção preventiva, constatou-se que em nenhuma das marquises analisadas foram realizadas algum tipo de manutenção preventiva. Os autores ainda verificaram que a manifestação patológica de maior ocorrência foi a infiltração com percentual de $30 \%$. Outras manifestações como mofo e bolor, fissuras e trincas, deterioração do concreto, deterioração da camada de revestimento e corrosão da armadura apresentaram $26 \%, 22 \%, 9 \%, 9 \%$ e $4 \%$ respectivamente. Com isso, Felten et al. (2013) constataram que a partir das manifestações patológicas analisadas, 39\% dos casos apresentaram gravidade média.

Nos estudos de Schardong e Pagnussat (2011) em que foram analisadas as lajes que constituíam o edifício, entre 18\% e 30\% desses elementos estruturais apresentavam algum tipo de degradação visível. Os autores realizaram o mapeamento das causas das manifestações patológicas e verificaram que para as lajes, a sua deformabilidade relacionada à espessura de concreto, juntamente com o embutimento de tubulações elétricas influenciaram no surgimento de fissuras. Também foi constato que a incorreta execução do sistema de impermeabilização das vigas de fundação gerou a percolação de umidade nas paredes, bem como a ausência de vergas e contra vergas resultou na ocorrência de fissuras junto às esquadrias.

De acordo com BÖES (2017) os riscos das anomalias e falhas das edificações podem ser avaliados por inspetores a partir de metodologias que identifiquem tais riscos. Segundo o autor, o método GUT (gravidade, urgência e tendência) é utilizado uma escala de notas para atribuir a gravidade ao problemas, sendo de 1 a 5 em ordem crescente de menos grave para mais grave. Com essa atribuição, é definido assim a prioridade da anomalia ou falha. Nos estudos de Soares et al. (2019) em que foi aplicada a metodologia da matriz GUT, os elementos relacionados à instalação elétrica apesentaram maior prioridade devido problemas como fiação exposta que poderia provocar curtoscircuitos e choques.

O objetivo do presente trabalho é analisar as manifestações patológicas das escolas públicas da região Leste do estado do Rio Grande do Norte e apresentar possíveis correções e soluções para tais problemas utilizando a metodologia da matriz GUT - Gravidade, Urgência e Tendência.

\section{METODOLOGIA}


Para realização do presente estudo foram avaliadas 3 escolas públicas do estado do Rio Grande do Norte. A primeira foi intitulada de X e está situada no município de Parnamirim, a segunda foi intitulada de Y e está localizada no município de São Miguel do Gostoso, e a terceira foi intitulada de $\mathrm{Z}$ e está localizada no município de Natal. A metodologia do estudo foi divindade em quatro etapas (04) apresentadas na Figura 1.

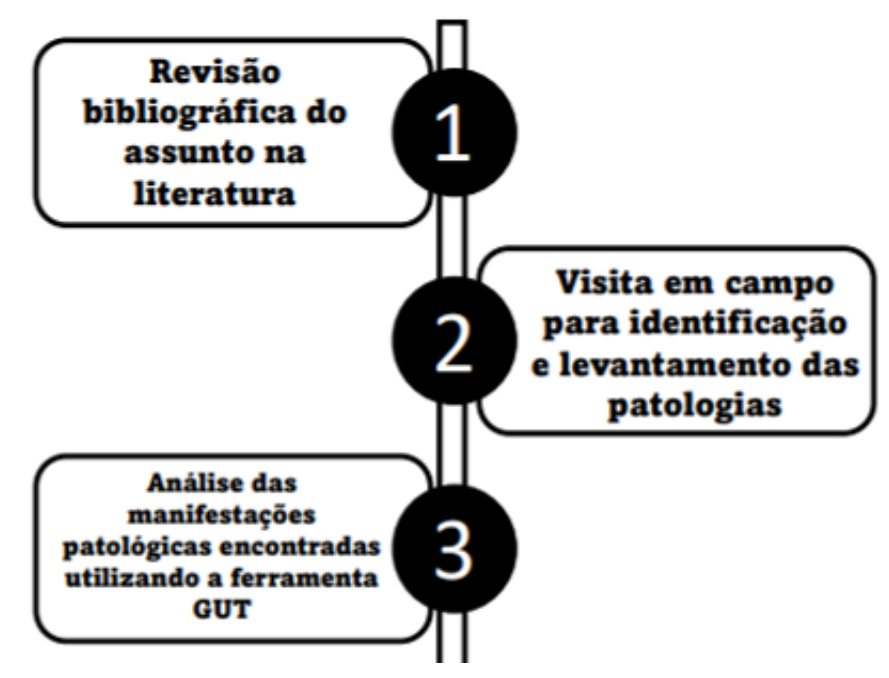

Figura 1: Metodologia utilizada no estudo.

Fonte: Autores, 2021.

Iniciou-se uma revisão sistemática sobre o tema manifestações patológicas na literatura, onde foram lidos alguns trabalhos científicos pesquisados nas bases de pesquisa Scielo, Research Gate e Google acadêmico. Após a leitura, os estudos foram catalogados de forma sistemática em uma planilha de Excel para auxiliar na etapa de escrita.

$\mathrm{Na}$ segunda etapa, foi realizada uma visita in loco, onde o objetivo era identificar, de maneira prévia, as manifestações patológicas presentes nas edificações através de registros fotográficos.

Na terceira etapa, a partir dos registros fotográficos coletados, clasificados e analizados, fez-se um levantamento das anomalias presentes nas estruturas e, em seguida, foi aplicada a ferramenta da matriz GUT.

A matriz divide-se em Gravidade, Urgência e Tendência - GUT. No quesito gravidade, é avaliado o quão grave o problema em questão pode se tornar caso nenhuma decisão seja tomada. No quesito urgência é avaliado o quão urgente é tomar uma decisão para resolver o problema em questão. No quesito tendência é avaliada a tendência de evolução do problema em questão caso nenhuma providência seja tomada.

Segundo De Azevedo Pereira et al (2014) e Braga et al (2019) a metodologia GUT é de extrema importância e utilidade para resolução de problemas, visto que é possível classificar os problemas encontrados de acordo com sua gravidade e assim traçar as melhores estratégias para solução.

Na Tabela 1, temos a ilustração da metodologia da matriz GUT utilizada no presente estudo, com as devidas classificações de Gravidade, Urgência e Tendência. Na última fase esta do estudo, após realizada a classificação através da matriz GUT, foram levantadas possíveis soluções para as manifestações patológicas encontradas nas pesquisas in loco, objetivando tratar e prevenir a evolução dessas manifestações, evitando danos maiores na estrutura. 


\section{RESULTADOS}

\subsection{Escola X}

\subsubsection{Levantamento das manifestações patológicas}

\begin{tabular}{|c|c|c|c|c|}
\hline \multirow[b]{2}{*}{ Fator } & G - Gravidade & U - Urgência & T - Tendência & \multirow[b]{2}{*}{$G \times U \times T$} \\
\hline & $\begin{array}{c}\text { Gravidade das } \\
\text { consequências caso } \\
\text { nenhuma decisão seja } \\
\text { tomada }\end{array}$ & $\begin{array}{l}\text { Quão urgente é } \\
\text { tomar uma } \\
\text { decisão }\end{array}$ & $\begin{array}{c}\text { Tendência do } \\
\text { problema em se } \\
\text { agravar caso nada } \\
\text { seja feito }\end{array}$ & \\
\hline 1 & Sem Gravidade & Pouco & $\begin{array}{l}\text { Não há tendencia de } \\
\text { agravamento }\end{array}$ & $1 \times 1 \times 1=1$ \\
\hline 2 & Levemente & Levemente & Longo prazo & $2 \times 2 \times 2=8$ \\
\hline 3 & Mediana & $\begin{array}{l}\text { O mais breve } \\
\text { possível }\end{array}$ & Médio prazo & $3 \times 3 \times 3=37$ \\
\hline 4 & Muito & Muito & Curto prazo & $4 \times 4 \times 4=64$ \\
\hline 5 & Extremamente & Extremamente & Imediatamente & $5 \times 5 \times 5=125$ \\
\hline
\end{tabular}

Tabela 1: Matriz GUT utilizada para avaliação.

Fonte: Autores, 2021.

É possível observar nas Figuras 2 e 3 que as seções de todos os pilares da área externa da escola se encontram em degradação, com o agravante da exposição das armaduras. Se faz necessária uma inspeção especifica para determinar a causa exata do problema, mas pressupõe-se que a degradação tenha começado com a abertura fissuração e trincas que evoluíram até chegar na situação atual. $\mathrm{Na}$ Figura 4 observa-se que após o desplacamento do revestimento cerâmico, o elemento estrutural ficou vulnerável, ocasionando assim a exposição da armadura. Observa-se na Figura 5 a exposição da armadura, bem como trincas e fissurações ao longo da peça estrutural, e nota-se também que o espaçamento entre as armaduras não foi adequado.

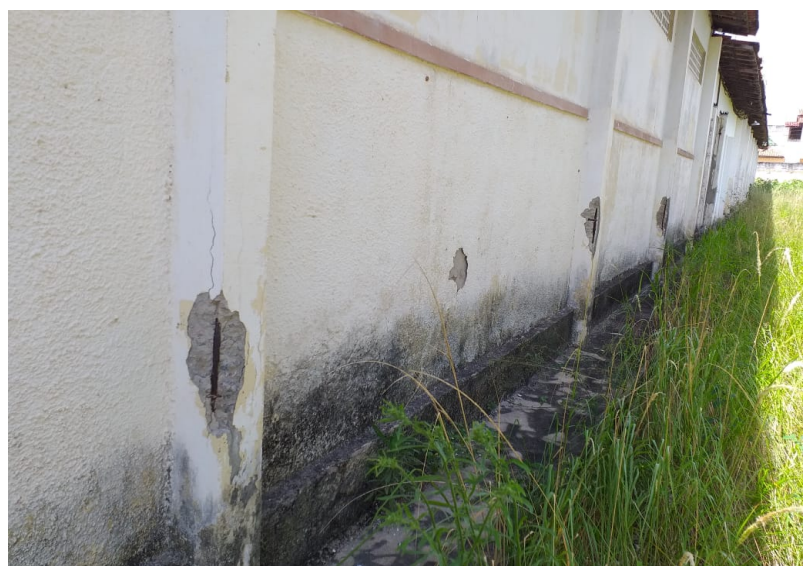

Figura 2: Manifestações patológicas.

Fonte: Autores, 2021.

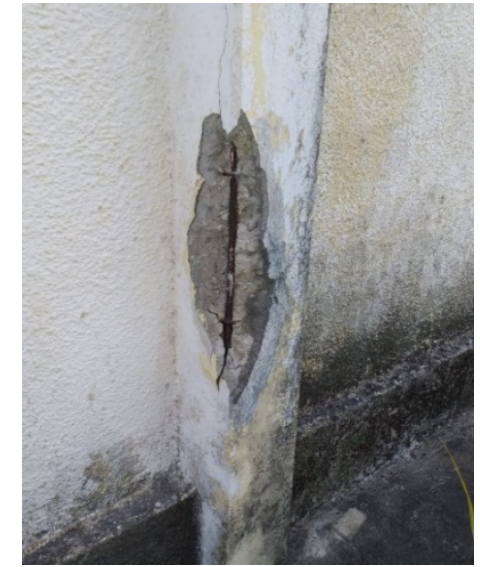

Figura 3: Manifestações patológicas. Fonte: Autores, 2021. 


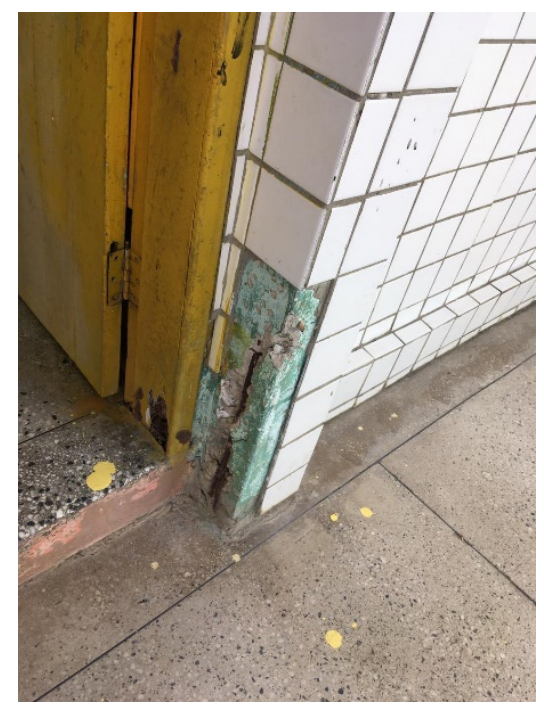

Figura 4: Manifestações patológicas Fonte: Autores, 2021.

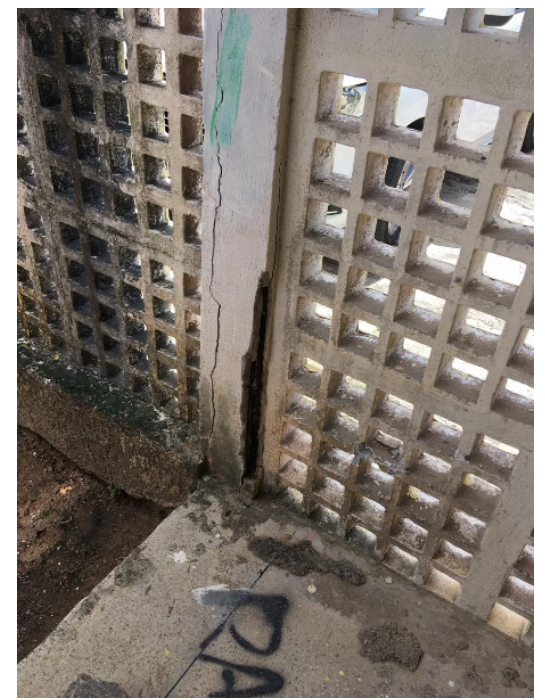

Figura 5: Manifestações patológicas Fonte: Autores, 2021.

Na Figura 6 há ocorrência de manifestações patológicas no revestimento da parede interna do muro lateral da escola que pôde ter sido ocasionada por emprego de materiais de baixa qualidade e/ou falhas no processo executivo, visto que é possível perceber uma desagregação da camada de pintura e reboco do muro, além de sujidade na camada de pintura existente. Já na Figura 7 observa-se sujidade na parede externa na qual pode ser justificada pelo contato constante com a água e/ou umidade do ar-condicionado instalado na parte superior da parede, causando assim infiltrações.

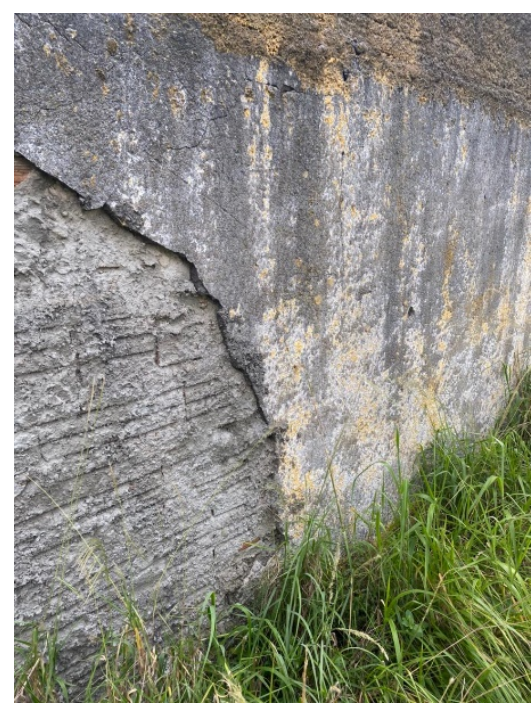

Figura 6: Manifestações patológicas Fonte: Autores, 2021.

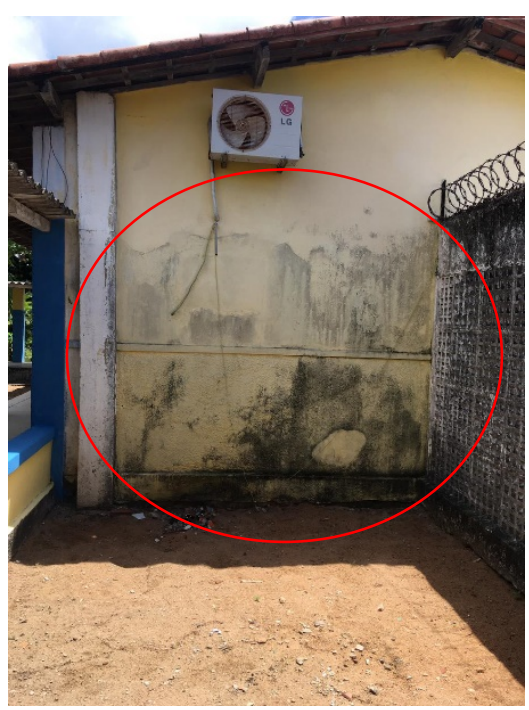

Figura 7: Manifestações patológicas Fonte: Autores, 2021.

Verifica-se na a Figura 8 o desplacamento cerâmico na parede externa de uma das salas de aula da escola. Sugere-se que seja realizado uma investigação mais detalhada para assim explicar a causa do surgimento da manifestação patológica. 


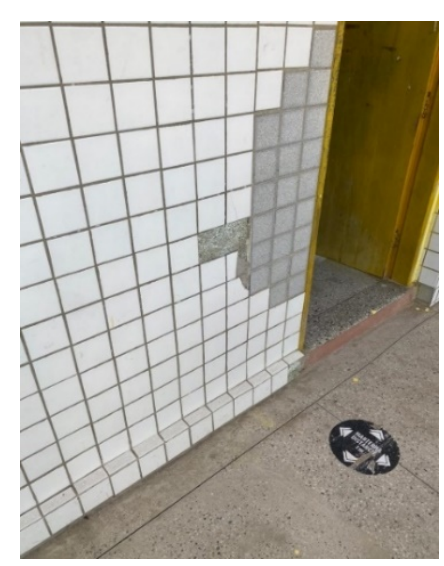

Figura 8: Manifestações patológicas Fonte: Autores, 2021.

\subsubsection{Análise das manifestações patológicas utilizando o método GUT}

\begin{tabular}{|c|c|c|c|c|c|c|}
\hline Escola & Foto & Descrição & G & U & T & GUT \\
\hline $\mathrm{X}$ & 2 & Trincas, fisuras e exposição da armadura & 5 & 5 & 5 & 125 \\
\hline $\mathrm{X}$ & 3 & Trincas, fisuras e exposição da armadura & 5 & 5 & 5 & 125 \\
\hline $\mathrm{X}$ & 4 & Trincas, fisuras e exposição da armadura & 5 & 5 & 5 & 125 \\
\hline $\mathrm{X}$ & 5 & Trincas, fisuras e exposição da armadura & 5 & 5 & 5 & 125 \\
\hline $\mathrm{X}$ & 6 & Desagregação das camadas de revestimento & 3 & 2 & 2 & 18 \\
\hline $\mathrm{X}$ & 7 & Sujidade e infiltração na pintura & 2 & 2 & 2 & 8 \\
\hline $\mathrm{X}$ & 8 & Desplacamento cerâmico & 2 & 3 & 3 & 18 \\
\hline
\end{tabular}

Tabela 2: Análise das manifestações patológicas.

Fonte: Autores, 2021.

Para aplicação da metodologia da matriz GUT, as manifestações patológicas encontradas na visita in loco foram divididas em grupo: Trincas, fissuras e exposição da armadura; Desagregação das camadas de revestimento; sujidade e infiltração da pintura e; Desplacamento cerâmico. Cada grupo representa o tipo de manifestação patológica observada durante a inspeção visual in loco. Como apresentado na Tabela 2, as manifestações patológicas foram analisadas e avaliadas de acordo com os critérios adotados, sendo em maioria as manifestações das Figuras 2, 3, 4 e 5 as que necessitam de uma tomada de decisão mais urgente, devido a gravidade das mesmas e tendência de agravamento. As manifestações referentes a revestimentos foram consideradas não tão urgentes, mas que podem se agravar em longo e médio prazo.

\subsection{Escola Y}

\subsubsection{Levantamento das manifestações patológicas}


No levantamento dos principais problemas encontrados na escola $Y$, podemos observar nas Figuras 9, 10, 11 e 12, fissuras e degradação do concreto que levam a exposição das armaduras. Neste caso, uma possível causa pode que estrutura tenha sofrido choques mecânicos. Outra possível causa pode estar relacionada a uma área do pilar que sofre maiores ataques de umidade, fazendo que a estrutura esteja submetida a percolação de água e ocasionando processos corrosivos da armadura.

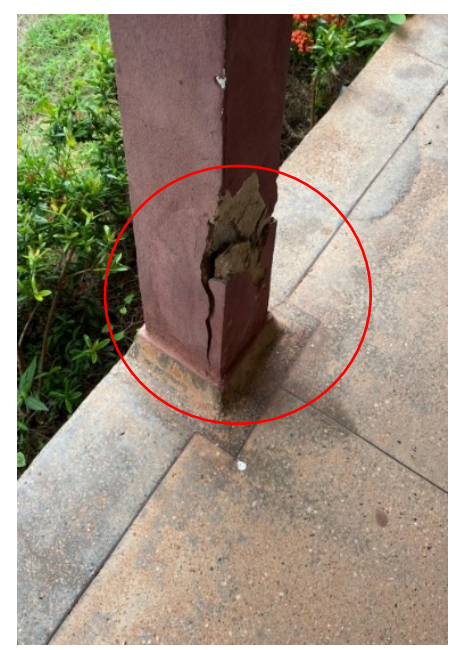

Figura 9: Manifestações patológicas Fonte: Autores, 2021.

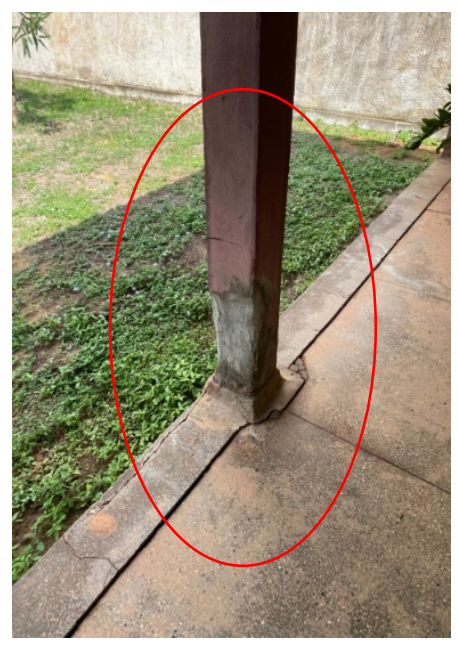

Figura 10: Manifestações patológicas Fonte: Autores, 2021.

Outros problemas encontrados foi o desplacamento cerâmico nas paredes (Figura 13). Nota-se uma execução inadequada da aplicação da argamassa de assentamento ou baixa qualidade do material utilizado. Na Figura 14 é possível observar patologias nas paredes que apresentam azulejos danificados, onde as possíveis causas podem ter sido de choques mecânicos.

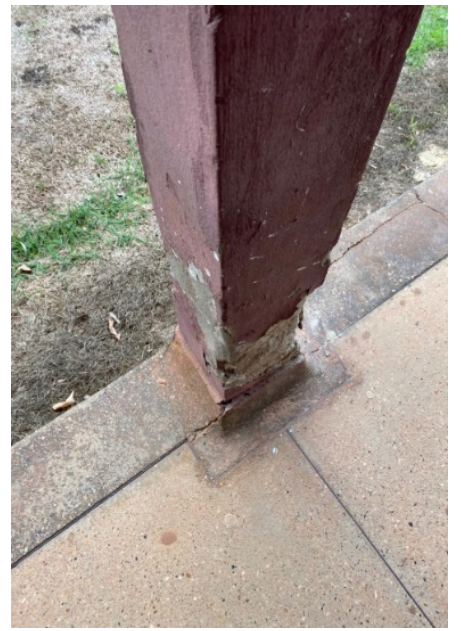

Figura 11: Manifestações patológicas Fonte: Autores, 2021.

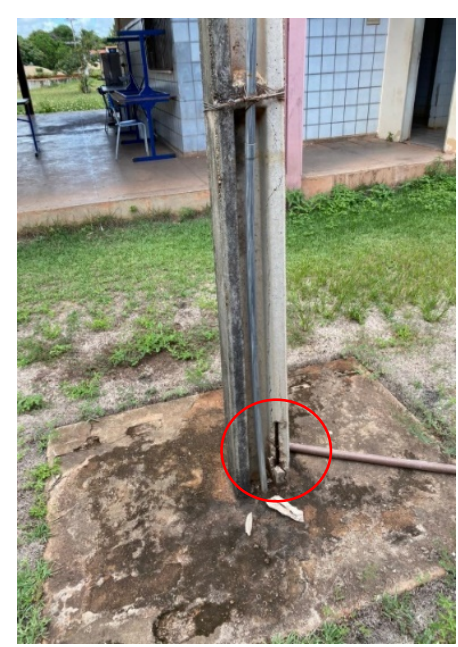

Figura 12: Manifestações patológicas Fonte: Autores, 2021. 
Observa-se nas Figuras 15 e 16 infiltrações nas paredes internas, que podem ter sido ocasionadas por falhas no processo executivo, como por exemplo, ausência de rufos, pingadeiras e impermeabilização. Ainda na Figura 15, pode-se observar que parte do forro de PVC encontra-se danificado.

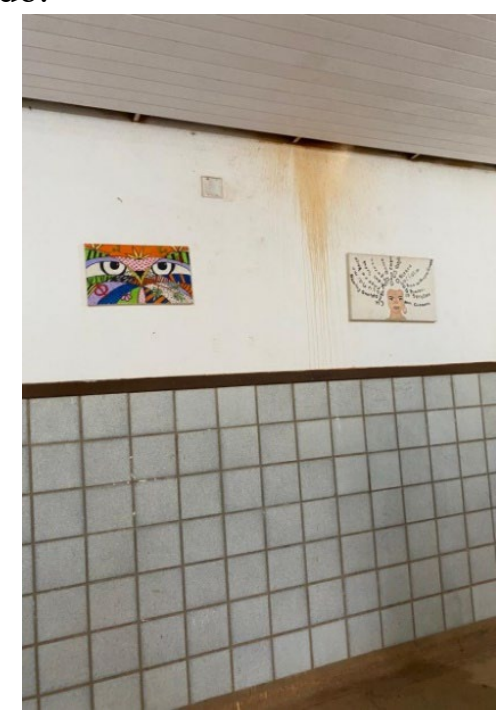

Figura 15: Manifestações patológicas Fonte: Autores, 2021.

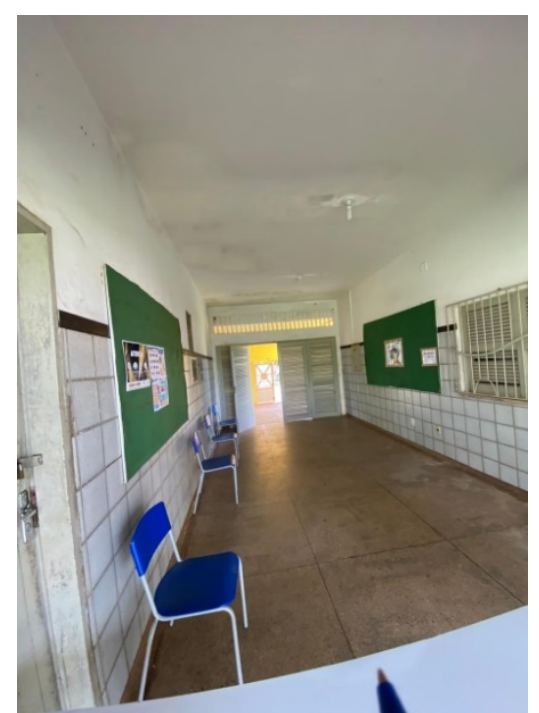

Figura 16: Manifestações patológicas Fonte: Autores, 2021.

Na Figura 17 é possível observar pequenas fissuras na alvenaria de vedação. A possível causa dessa patologia pode ter sido ocasionada a partir de uma execução imprópria do dispositivo de ancoragem da grade de proteção, visto que é necessário embutir a ferragem diretamente na alvenaria de vedação.

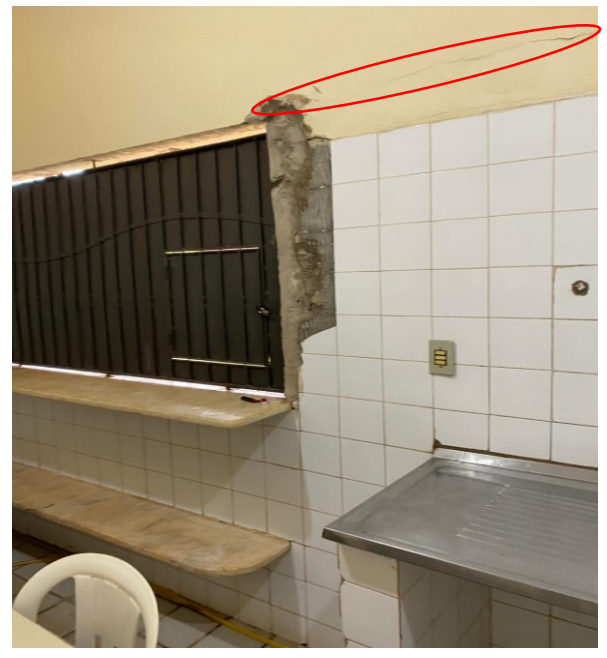

Figura 17: Manifestações patológicas Fonte: Autores, 2021.

\subsubsection{Análise das manifestações patológicas utilizando o método GUT}

Analogamente ao que foi realizado como metodologia para a Escola X, foi realizado na Escola $\mathrm{Y}$ e Z. As manifestações patológicas encontradas na visita in loco foram divididas em grupo: Fissuras e quebra do concreto; Desplacamento cerâmico; Revestimento cerâmico danificado; Infiltração e remoção do forro PVC; Infiltracão e trincas e fisuras. Cada grupo representa o tipo de manifestação 
patológica observada durante a inspeção visual in loco. Como apresentado na Tabela 4, as manifestações patológicas foram analisadas e avaliadas de acordo com os critérios adotados da metodologia matriz GUT. Vale ressaltar e dar ênfase nas manifestações de fissuras e quebra do concreto, onde estas foram avaliadas com os maiores níveis de gravidade, urgência e tendência.

\begin{tabular}{|c|c|c|c|c|c|c|}
\hline Escola & Foto & Descrição & G & U & T & GUT \\
\hline Y & 9 & Fisuras e quebra do concreto & 5 & 5 & 5 & 125 \\
\hline Y & 10 & Fisuras e quebra do concreto & 5 & 5 & 5 & 125 \\
\hline Y & 11 & Fisuras e quebra do concreto & 5 & 5 & 5 & 125 \\
\hline Y & 12 & Fisuras e quebra do concreto & 5 & 5 & 5 & 125 \\
\hline Y & 13 & Desplacamento cerâmico & 2 & 3 & 3 & 18 \\
\hline Y & 14 & Revestimento cerâmico danificado & 2 & 3 & 3 & 18 \\
\hline Y & 15 & Infiltração e remoção do forro PVC & 4 & 4 & 4 & 64 \\
\hline Y & 16 & Infiltração & 2 & 2 & 2 & 8 \\
\hline Y & 17 & Trincas e fissuras & 3 & 2 & 2 & 18 \\
\hline
\end{tabular}

Tabela 4: Análise das manifestações patológicas Fonte: Autores, 2021.

\subsection{Escola Z}

\subsubsection{Levantamento das manifestações patológicas}

Para a Escola Z, destaca-se ocorrências de problemas patológicos conforme as Figuras 18 e 19. Nota-se possíveis infiltrações pela cobertura, resultando em uma especie de bolor junto ao material do forro.

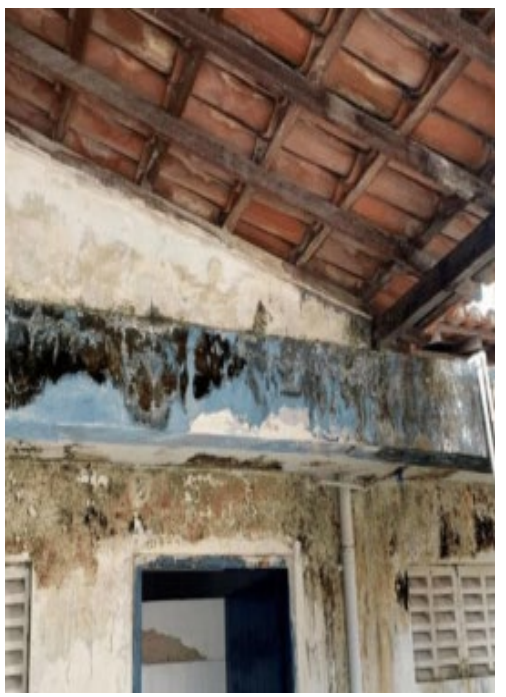

Figura 18: Manifestações patológicas Fonte: Autores, 221.

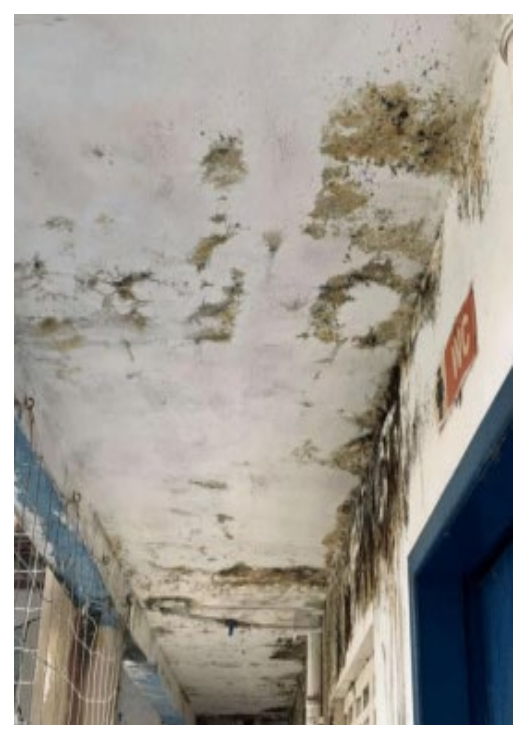

Figura 19: Manifestações patológicas Fonte: Autores, 2021.

Verificou-se outros problemas como a queda de reboco da parede conforme Figuras 20 e 21, que pode ter sido causada pela ausência do esboço como elemento construtivo, ou seja, falta de aderência da e substrato. 


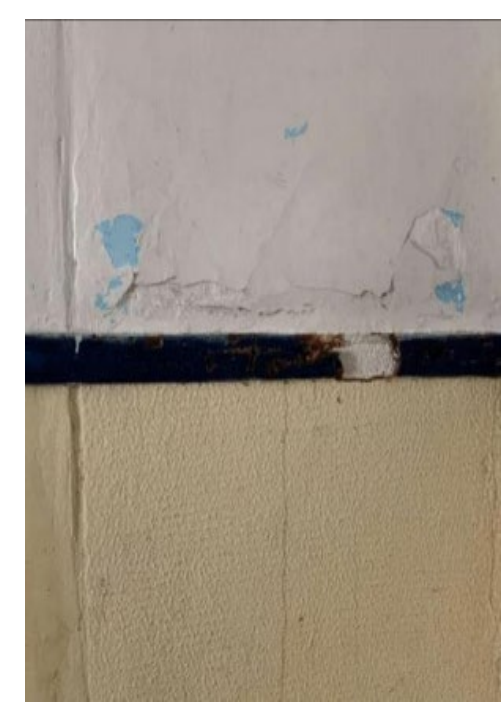

Figura 20: Manifestações patológicas Fonte: Autores, 2021.

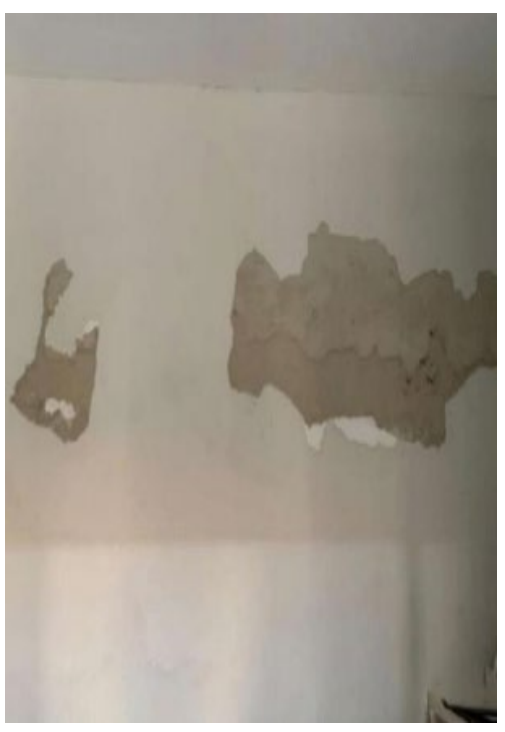

Figura 21: Manifestações patológicas Fonte: Autores, 2021.

\subsubsection{Análise das manifestações patológicas utilizando o método GUT}

\begin{tabular}{|c|c|c|c|c|c|c|}
\hline Escola & Foto & Descrição & G & U & T & GUT \\
\hline$Z$ & 18 & Infiltrações em paredes & 5 & 5 & 5 & 125 \\
\hline$Z$ & 19 & Infiltrações no teto & 5 & 5 & 5 & 125 \\
\hline$Z$ & 20 & Descolamento da pintura e reboco & 3 & 3 & 3 & 27 \\
\hline$Z$ & 21 & Descolamento da pintura & 2 & 2 & 2 & 8 \\
\hline
\end{tabular}

Tabela 6: Análise das manifestações patológicas

Fonte: Autores, 2021.

$\mathrm{Na}$ escola Z, o grupo das manifestações patológicas encontradas na visita in loco foram divididas em: Infiltrações em paredes; infiltrações em teto; Descolamento da pintura e reboco e; Descolamento da pintura. Como apresentado na Tabela 6, as manifestações patológicas foram analisadas e avaliadas de acordo com os critérios adotados da metodologia matriz GUT. Foi constatado a presença de infiltrações em paredes e tetos (Figuras 18 e 19), sendo estas avaliadas como extremamente grave e urgente. As manifestações relacionadas ao descolamento de pintura e reboco foram avaliadas com uma gravidade mediana e que a tomada de decisão deve ser mais breve possível dentro de um médio prazo. Quanto ao descolamento apenas da pintura (Figura 21), foi avaliada como uma gravidade leve devido a manifestação patológica apresentar pequena influência no comprometimento do desempenho do sistema como um todo.

\section{CONCLUSÕES}

Diante da avaliação das manifestações patológicas através da metodologia da matriz GUT, podese observar quais as ocorrências afetam o comprometimento do desempenho do sistema, conforme o grau de gravidade, urgência e tendência de cada tipo de manifestação. 
Observou-se que em algumas situações, as ocorrências foram originadas devido a falhas de execução e de emprego de materiais, e que os avanços das manifestações ocorreram devido à ausência de uma manutenção corretiva logo após os indícios do surgimento da manifestação. A matriz GUT foi imprescindível para que fosse possível mensurar a gravidade do problema patológico, bem como a urgência para se tomar uma decisão e verificar qual a tendencia que a manifestação poderia apresentar em caso de que nenhuma medida seja realizada para conter a manifestação patológica. Isso possibilitou designar quais manifestações são mais graves e necessitam de maior atenção.

Com isso, o presente trabalho atingiu aos objetivos propostos quando as manifestações analisadas foram classificadas e identificadas através da metodologia da matriz GUT. 


\section{REFERÊNCIAS}

Arivabene, A. C. Patologias em Estruturas de Concreto Armado - Estudo de Caso. Revista Especialize On-line IPOG, Goiânia, v. 01, n. 10, 2015.

BÖES, Jeferson Spiering. Inspeção Predial: uma metodologia integradora para identificação e priorização de manifestações patológicas em edificações. XIII Congresso Internacional sobre Patologia e Reabilitação de Estruturas. Crato, 2017.

CARASEK, H.; CASCUDO, O. Descolamento de Revestimentos de Argamassa Aplicados sobre Estruturas de Concreto - Estudos de casos brasileiros. $2^{\circ}$ Congresso Nacional de Argamassa de Construção. Lisboa, 2007.

FELTEN, D.; GRAHL, K. F. S.; LONDERO, C. Levantamento de manifestações patológicas em marquises de concreto armado. Revista Thêma Et Scientia, Cascavel, v. 3, n. 1, p. 69-78, 2013.

HELENE, Paulo Roberto Lago. Manual para Reparo, Reforço e Proteção de Estruturas de Concreto. São Paulo, Pini, 1997.

INSTITUTO BRASILEIRO DE AVALIAÇÕES E PERÍCIAS DE ENGENHARIA DO PARANÁ. Inspeção e Manutenção predial. Paraná, 2016.

INSTITUTO BRASILEIRO DE AUDITORIA DE ENGENHARA. OT-003/2015-IBRAENG: Inspeção Predial e Auditoria Técnica Predial. Fortaleza, 2015.

Martins, J. F. A.; Fioriti, C. F. Investigação de manifestações patológicas em sistemas estruturais de concreto armado: estudo de caso em edificação pública. Revista Brasileira de Iniciação Científica, Itapetinga, v. 3, n. 4, p. 90-102, maio 2016.

SILVA, R. A.; OLIVEIRA, D. R.; VIEIRA, R. B.; BRAGA, B. S. de M.; Levantamento quantitativo de manifestações patológicas de fachadas em edificações multipavimentos na área urbana central de Patos de Minas - MG. Congresso Técnico Científico da Engenharia e da Agronomia. Foz do Iguaçu, 2016.

Soares, C. S.; Albuquerque, T. P.; dos Santos, F. G.; Farias, B. G. S.; da Cunha, C. G. S.; Crispim, H. C. Manifestações patológicas nas salas de aula da escola agrícola Assis Chateaubriand UEPB. Brazilian Applied Science Review. Curitiba, v. 3, n. 1, p. 145-155, jan./fev. 2019. 